\title{
The Promotion of Digital Economy to Development of China's Service Trade
}

\author{
Ning $\mathrm{Li}^{1, *}$ \\ ${ }^{I}$ Institute of Northeast Asian Studies of Heilongjiang Provincial Academy of Social Sciences, Harbin, China. \\ *Corresponding author. Email: houyi1206@163.com
}

\begin{abstract}
In recent years, China's digital economy has made great progress. Online shopping, Alipay, and shared bicycles are the epitome of digital economic development achievements. With the popularity of mobile Internet and smart phones, the digital economy is changing the way of life of the Chinese people from daily shopping to smart transportation, from commodity trading to new government governance. At present, China's digital economy has entered a golden period and is facing three rare opportunities for policy dividend release, industrial transformation and economic transformation. The research purpose is analysing the role of digital economy in promoting China's service trade. The article used cross-discipline research methods, such as comparative method, statistical research, and quantitative analysis. The study found that the the digital economy has already driven the transformation and upgrading of China's service industry. At the same time, China should accelerate the digital transformation services, to meet the opportunities and challenges of the global digital economy. It should also actively promote research on core technologies of digital infrastructure, form a first-class research team, increase investment in research and development of core technologies of digital infrastructure, and strive to make breakthroughs in cutting-edge and basic core technologies.
\end{abstract}

Keywords: China, Digital economy, Service trade, Transformation.

\section{INTRODUCTION}

In the era of network and digital economy, the development and penetration of digital technology has changed the way and content of trade and promoted the rise and development of global digital trade. Digital trade is divided into two parts: digital goods trade and digital service trade. Concerning the digital goods trade represented by e-commerce, China ranks among the top in the world and has strong competitiveness; however, concerning the digital service trade represented by information technology services and digital content services, China is still in its infancy and its competitiveness is relatively weak [1]. Therefore, strengthening the exploration of theories and policies related to digital service trade, analysing the status quo and existing problems of my country's digital service trade development, and proposing high-quality development policy recommendations will not only greatly promote my country from a digital trading country to a digital trading power, but also has important strategic significance for promoting the high-quality development of service trade, building a new pattern of full opening, and building a modern economic system.

The application of new technologies such as $5 \mathrm{G}$ and artificial intelligence and the cultivation of new economic models such as mobile payment cannot be separated from the support of the mass market. The massive data generated in such a huge market can effectively stimulate the birth of new technologies and new economic models[2]. In the digital age, China's ability to accumulate and utilize data will be in the forefront of the world for a long time, and the Chinese market will become a unique stage for innovation entrepreneurs around the world.

\section{METHODOLOGY}

The article used cross-discipline research methods, such as comparative method, statistical research, and quantitative analysis. Using the comparative method, 
the potential of China's digital economy was determined. By comparison, we can find that compared with the developed countries of the United States, Japan and Europe, China's digital economy potential has huge room for exploration. According to the 2018 statistics, the US digital economy has a GDP share of $59.2 \%$, Japan $45.9 \%$, the UK $54.5 \%$, and China only $30.3 \%{ }^{1}$. Compared with developed countries, the development of China's digital economy is full of stamina. In October 2018, the Shanghai Academy of Social Sciences released the "Global Digital Economy Competitiveness Development Report (2018)". The report ranks the digital economy competitiveness of 50 countries around the world, with the United States, China, and Singapore being among the top three. Compared with the previous year, the gap between China and the United States in the competitiveness of the digital economy is shrinking. Among the top 100 global digital economy companies, 29 are American companies, 20 Japanese companies, and 11 Chinese companies. Among the top ten, there are two from China [3]. This series of data not only reflects the achievements of China's development of the digital economy, but also shows the great potential of the future development of the digital economy. China's huge domestic market, increasingly sophisticated infrastructure, and institutional advantages of focusing on major events have created favorable conditions for the development of the digital economy.

\section{RESULTS}

The combination of infrastructure and digital economy constitutes a network of people, goods and information exchanges across China. China's expressway network and high-speed railway network have grown to the world's number one, which greatly promotes the interconnection of people and things [4]. China's broadband coverage and mobile network coverage have rapidly increased, ranking among the best in the world, effectively facilitating the exchange of information. China now has the largest group of Internet users and smartphone users in the world. The development results have effectively reduced the cost of digital economic development. No matter where they are, the Chinese people can directly connect with the national market through the Internet. A vast majority of consumers are both producers and providers of big data, and at the same time be the beneficiaries of big data [5].

\footnotetext{
${ }^{1}$ P. Yan, Xu Jinhai, Promote the high-quality development of China's digital service trade, China Economic and Trade Guide, vol. 13, 2020, pp.40-43.
}

China must promote the in-depth development of "Internet + " and promote the growth of the digital economy, so that enterprises can benefit widely and the people will generally benefit. In September 2018, the National Development and Reform Commission of China issued the "Guiding Opinions on Developing Digital Economy Stability and Enlarging Employment", proposing "to seize development opportunities, vigorously develop digital economy stability and expand employment, and promote economic transformation and upgrading and employment promotion." [6]. China's huge domestic market will also fully play its role and more consumption potential will be tapped, which fully reflects the institutional advantages of China's concentrated efforts to do big things, so that the results of the digital economy will fully benefit the people.

China's economy has shifted from a high-speed growth stage to a high-quality development stage, and is in the process of transforming the development mode, optimizing the economic structure, and transforming the growth momentum. Promoting highquality development is a fundamental requirement for determining development ideas, formulating economic policies, and implementing macroeconomic regulation at present and in the future. To promote the high-quality development of China's economy, we must adapt to the new round of scientific and technological revolution and industrial transformation in the world, lead China's industrial structure to develop in the direction of high-end and modernization, and continue to climb to the middle and high-end on the ladder of global value chain [7]. The digital economy can effectively help the supply side and the demand side to match precisely and intelligently, and promote the supply side structural reform. Data is the most critical production factor in the digital economy, and data from the demand side helps the supply side better judge the market and make decisions about production. From an economic point of view, the digital economy will effectively solve information asymmetry, thus helping to solve problems that are difficult to solve by traditional means, such as low production efficiency and relative production surplus [8]. The development of the digital economy is not limited to information-related industries, but it can also drive the construction of a more flexible production, operation and management system for traditional industries and achieve transformation and upgrading. The development of the digital economy is not limited to online related industries, but can be integrated with the real economy to effectively help smooth the entire process channel from production to sales, thereby improving efficiency. The digital economy can 
effectively help the government to serve the people and govern the society accurately and intelligently, and to promote the modernization of the national governance system and governance capacity. With the development of the digital economy, the government's service and governance methods have also undergone profound changes. The Chinese government has repeatedly stressed that accelerating the promotion of "Internet + " government services is a key move to deepen the administration of decentralization, integration, and optimization of service reforms, which will help improve government efficiency and transparency and reduce institutional transaction costs.

Today, with the changing international situation, the digital economy will help the Chinese economy move towards the high end of the global value chain. China's leading big data accumulation capability in the world will effectively help technological innovation and economic transformation, and help China to occupy a favorable position in international competition. This will also give China a valuable opportunity to participate in the development of international standards around the world, and try its best to get rid of the constraints in the industrial age [9]. The digital economy fits into the new development concept of innovation, coordination, green, openness and sharing. As the Chinese economy faces a new era of kinetic energy transformation and shifts to high-quality development, the digital economy is becoming a major strategic development direction of China and will gradually grow and develop. The Chinese economy has achieved high quality development.

The digital economy will become a new historical stage in the development of human history after the agricultural economy and industrial economy [10]. It is the inevitable result of a new round of scientific and technological revolution and industrial transformation, representing the full integration of Internet technology, big data technology and intelligent technology application results in our production and life. The digital economy is an important support for adapting to, grasping and leading the new normal of economic development. The development of the digital economy, the birth of new industries, new formats, new models, and the digital development of the service industry are new kinetics for economic development in the new era. China's digital economy has entered a stage of rapid development, taking digital knowledge and information as key production factors, and new technologies, new industries, new formats, and new models of the digital economy continue to emerge, especially in the prevention and control of the new crown pneumonia epidemic and the resumption of work. The digital economy has become a new driving force for social and economic development. According to the "White Paper on China's Digital Economy Development" issued by the China Academy of Information and Communications Technology, the scale of China's digital economy has increased from 16.16 trillion yuan in 2014 to 35.84 trillion yuan in 2019. The total scale of the digital economy as a proportion of GDP has increased from $26.1 \%$ in 2014 to $36.2 \%$ in 2019 (as shown in Figure 1). The digital economy has become an important part of China's national economic growth [11]. The continuous innovation of the Internet business model, the acceleration of the integration of online and offline services, and the accelerated pace of online of public services have become the driving force for the growth of netizens. In addition, the number of Internet users who purchase Internet wealth management products in China is huge, and the scale of online financial management of Monetary Funds has maintained rapid growth. At the same time, the intensive introduction of policies and strong supervision measures in the Internet financial industry has pushed the industry toward standardized development.

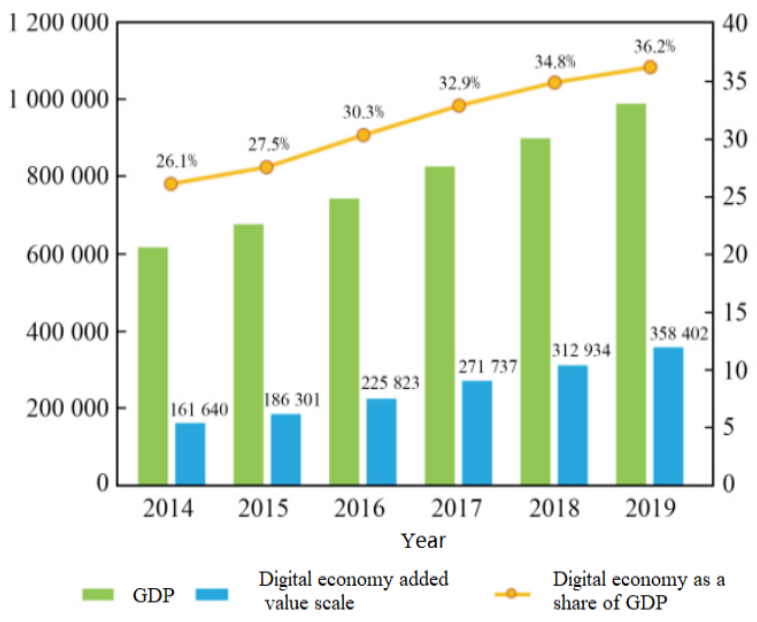

Figure 1 The contribution of China's digital economy to economic growth

According to the survey of the e-commerce transaction platform of the National Bureau of Statistics, the total amount of electronic transactions in China has increased significantly in the past five years [12]. In 2019, China's e-commerce transaction volume was 34.81 trillion yuan, nearly twice times that of 2015 (Figure 2). 


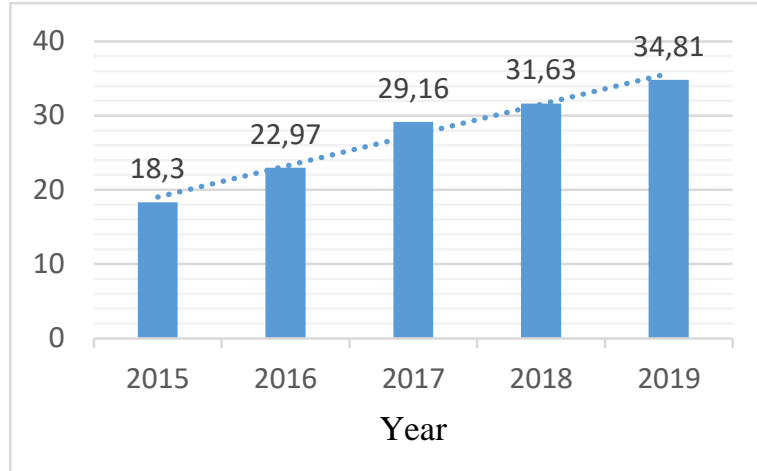

Figure 2 2015-2019 China e-commerce transaction volume, trillion RMB

In the online retail structure, the retail sales of physical-type networks totaled 6.31 trillion yuan, and the total retail sales of service-oriented networks reached 3.16 trillion yuan. The continuous innovation breakthrough of e-commerce service mode, technical form and empowerment efficiency is the main driving force for the rapid increase of income level. The rapid development of the digital economy has given birth to new formats. The digital economy characterized by "Internet +", e-commerce, digital content services, shared platforms and Internet finance is the new engine for China's economic transformation and upgrading, and the sustainable coordination of industry, agriculture and services. The development of the integration of power, the promotion of social synergy and innovation, the development of e-commerce economy is also an effective way to improve national competitiveness. The digital economy is not only a new kinetic energy for China's economy to improve quality and efficiency, but also a new blue ocean for China's economic transformation and growth.

At present, emerging enterprises represented by the Internet, big data, and artificial intelligence applications have gradually merged into the real economy, forming a new impetus for the online economic development and upgrading of China. The Internet and digitalization have promoted the transformation and upgrading of the traditional economy to the Internet economy, which has brought new development opportunities for China's economic development .Through the application of digital technologies represented by the Internet, big data and smart technologies, the integration of innovation in agriculture, industry and services, the optimization of economic structure, the improvement of product quality, the balance between demand and production, the reduction of costs, and the promotion of efficient development of the economy are inevitable ways for the high-quality development of China's economy. "Guiding Opinions of the State Council on Actively
Promoting "Internet + " Actions" clearly states that "Internet $+"$ is to integrate the innovation achievements of the Internet with various fields of economic and social development, so as to promote technological progress, improve efficiency and change organization, and enhance the innovation of the real economy and productivity, which can form a new form of economic and social development with a wider range of Internet-based infrastructure and innovation elements [13]. The "Internet + " key areas include: entrepreneurial innovation, collaborative manufacturing, modern agriculture, smart energy, inclusive finance, benefit-based services, efficient logistics, e-commerce, convenient transportation and green ecology. At present, these fields have achieved remarkable results in the digital development.

In recent years, the free trade pilot zone, the pilot area of deepening service trade innovation and development, the cross-border e-commerce comprehensive pilot zone, and the national import trade promotion innovation demonstration zone are actively developing new digital economy formats, building a digital economic infrastructure, exploring new policies for the digital economy and vigorously promoting mature experiences and models. These pilot projects have achieved good results in the development of the digital economy. In fact, the digital economy, as a pioneer in China's economic innovation and development, has already driven the transformation and upgrading of China's service industry. Through the development of the digitalization of the financial services industry, it will bring the financial product value chain, the continuous optimization of the enterprise supply chain and the ecological development of the industrial chain, enhance the core competitiveness of China's financial services industry, promote the digital innovation and development of financial services, and lead the digital transformation of China's financial services industry [14]. During the development of China's commercial banks, the five major banks have established diplomatic relations with Internet companies, and comprehensively transformed and developed digital banks. Zhejiang Internet Bank and other emerging Internet banks have successively been founded and relied on the Internet to carry out banking business. Commercial banks are constantly executing innovative development in digital business. The innovation and development of Internet finance characterized by payment has been very rapid and has had a big impact on traditional payment services.

The core technology competitiveness of digital infrastructure is not strong. From a global perspective, whether different countries or regions 
have the right to speak in the field of digital service trade and occupy a dominant position in the value chain and industrial chain, depends on whether different countries or regions have core technologies related to digital infrastructure. In fact, since mankind entered the era of network and digital economy, the core technology of digital infrastructure has become an important part of measuring the core competitiveness of a country. At present, developed economies represented by the United States, Europe, Japan, etc., control most of the core technologies of digital infrastructure and occupy a dominant position in digital service trade [15]. Although China has been accelerating the construction of digital infrastructure in recent years, it has also made significant achievements and recently proposed to accelerate the development of new infrastructure; but the objective fact that China has to face is that China still relies heavily on imports in some key core technologies, key components, basic software, high-end dedicated chips, smart terminal processors, etc., and the core technology of digital infrastructure is not competitive. Without breakthroughs in the core technology of digital infrastructure, the core problems faced by the development of digital services trade cannot be solved. Even if China will continue to grow in the total volume of digital service trade with the advantages of a large country and a large market in the future, it still has no right to speak in the field of digital service trade. The value distribution obtained in the global value chain of digital service trade is still limited.

The core technology competitiveness of digital infrastructure is not strong. The establishment of a scientific and standardized statistical system is the basic basis for promoting industrial development, conducting industry analysis, conducting theoretical research and formulating industrial development policies. Developed economies such as the United States and Europe, based on the statistical framework of the United Nations Conference on Trade and Development and the development of their own digital service trade, have established a relatively sound digital service trade statistics system, and implemented and updated data on the subdivisions of digital service trade. China has not yet established a statistical system for digital service trade. Data related to digital service trade is scattered in the statistics of different industries. It is difficult to obtain accurate data on digital service trade, and it is not authoritative. This is important for the government's supervision of digital service trade. Scholars carry out related theories and policy research, which have brought great problems. The statistics system of the digital service trade lags behind the practice of industrial development, which is also an important issue restricting the development of China's digital service trade.

Many enterprises in China have emerged representative of the digital economy in the fields of big data, Internet, artificial intelligence, financial technology, and new retail. The vigorous development of these emerging enterprises has brought a new driving force for the digital economy to the transformation and upgrading of traditional Chinese industries. At present, China's digital economy is extremely unevenly developed. It is at the forefront of international development in terms of ecommerce, inclusive finance, and shared economy. However, many aspects of the financial services industry are still in the early stages of development and require unremitting efforts. In the future, we will focus on the development of a digital financial management system characterized by big data sharing, a digital financial service system characterized by a financial supply chain, a digital financial customer system characterized by intelligent transaction services, and an inclusive financial system characterized by Internet finance.

\section{CONCLUSION}

China faces the golden opportunity of developing the digital economy, but it also faces challenges. For example, the core technical capabilities are lacking. The ZTE incident tells us that the further development and breakthrough of core technologies is imminent. Only by overcoming the difficulties of the core technology of digital infrastructure, China's digital service trade in the future can occupy a dominant position in the global value chain and have the right to speak. Furthermore, China should actively promote research on core technologies of digital infrastructure, establish a first-class research team, increase investment in research and development of core technologies of digital infrastructure, aim at breakthroughs in cutting-edge and basic core technologies, and break the core technology dependence of developed economies. What's more, China should support pragmatic development of digital service trade, speed up the construction of a basic software product system with independent intellectual property rights, and improve the supply of high-end software. There are restrictions on regulatory mechanisms, lack of laws and regulations, the lag of talent cultivation, etc., especially in the development of new formats, the challenges of subject responsibility, cross-border supervision, privacy protection, etc., which need to be gradually improved and solved through further reform and opening up, continuous innovation and development. The prospect of the digital economy is 
broad. The digital service of the financial services industry still needs to update knowledge, strengthen the core technology development capacity building, and build big data infrastructure capabilities. The financial services industry urgently needs digital integration and innovation in the innovation of financial service products and the ecologicalization of the financial service industry chain. Vigorously supporting and encouraging new technologies, new formats, new economic models and innovative development of new businesses, and promoting the transformation and upgrading of the financial services industry are important tasks for the financial industry in the future. At the same time, it is also necessary to play a leading role in the new digital economy, actively engage in the Belt and Road Initiative, and lead Chinese financial enterprises and various digital business platforms to go global and promote the international development of China's financial services industry.

\section{ACKNOWLEDGMENTS}

The work is supported by Heilongjiang provincial philosophy and social science fund project "Research on the construction of digital channels in our province's economic and trade cooperation with Russia in the new era" (20GJC198).

\section{REFERENCES}

[1] Ch. Xiuying, L. Sheng, Barrier Evaluation and Optimization Path of China's Service Trade Opening in the Digital Era, Shanghai Economics, June 2019, pp. 5-15.

[2] C. Rowley, I. Oh, The enigma of Chinese business: understanding corporate performance through managerial ties, Asia pacific Business review 26(5) (2020) 529-536. DOI: $10.1080 / 13602381.2020 .1843290$

[3] Y. Qiao, The Impact of Internet Popularization on Service Trade-Empirical Evidence from 152 Countries Around the World, Journal of Capital University of Economics and Business 02 (2018) 62-71. DOI: https://doi.org/10.13504/j.cnki.issn10082700.2018.02.007

[4] Zh. Guojun, Comparative Analysis of International Competitiveness of China, Japan and South Korea's Communication Service Trade, China Business 03 (2015) 99-101.

[5] T. Jing, Five Suggestions for Promoting the Development of my country's Telecom Service Trade, Service Outsourcing 09 (2017) 36-37.
[6] M. Fanglin, Zh. Yuanjun, Q. Yulan, Research on the Improvement Path of my country's Producer Service Trade International Competitiveness from the Perspective of Global Value Chains, Management Modernization 06 (2019) 20-26. DOI: $\quad$ https://doi.org/10.19634/j.cnki.111403/c.2019.06.006

[7] Zh. Sha, Development Trends of Global Medical Service Trade and China's Response Strategies, Price Theory and Practice 12 (2019) 27-30. DOI: $\quad$ https://doi.org/10.19851/j.cnki.CN111010/F.2019.12.015

[8] Ch. Wei, Digital Economy Empowers China's Service Trade, Service Outsourcing 05 (2019) 40-42.

[9] Xu Weicong, Li Junjiu, China's service trade development status, problems and countermeasures, Regional Economic Review 05 (2020) 122-130. DOI: ttps://doi.org/10.14017/j.cnki.20955766.2020 .0096

[10] Wu Zaihua, Research on the Development of China's Service Trade from the Perspective of Competitiveness, Economics and Management 11 (2006) 14-18.

[11] Wu Lichao, Analysis of the Status Quo of China's Service Trade International Competitiveness and Improvement Countermeasures, Journal of Capital University of Economics and Business 01 (2008) 96-100.

[12] P. Changhong, Strategic Thinking on the Highquality Development of China's Service Trade, Chinese Foreign Investment 23 (2019) 22-24.

[13] M. Guanqun, Development Status and Trend Outlook of Global Digital Service Trade, Globalization 04 (2020) 62-77. DOI: https://doi.org/10.16845/j.cnki.ccieeqqh.2020.04 .005

[14] B. Jinhao, Liu Ru, Development Trends and Future Opportunities of Digital Economy, People's Forum, vol. 20, 2020, pp.80-81.

[15] G. Yue, Analysis of Industrial Structure Optimization Strategy in the Background of Digital Economy, Business Economic Research, 12 (2019) 176-178. 